\title{
Historia oral. Las razones y pasiones de Porfirio Muñoz Ledo
}

Alberto Aziz Nassif॰

doi: http://dx.doi.org/10.32870/espiral.v26i74.7074.g6157

Porfirio Muñoz Ledo (PML) ha formado parte del México contemporáneo desde hace décadas. Ha sido uno de los políticos más destacados del país, y ha tenido intervenciones importantes en el ámbito internacional, como en las Naciones Unidas.

Dicho esto, ¿cuánta historia hay en la narración de su vida, que abarca cincuenta y cinco años y se cuenta a lo largo de un libro de novecientas cuarenta páginas? ¿Se trata de un personaje que se mira al espejo, o está en el diván?

A pesar de la dimensión considerable del material, una vez que la lectura de este libro inicia el interés crece, no porque se lea como una novela, sino porque tiene una serie de circuitos que conectan para adentrarse en una vida pública que ha sido multifacética, llena de matices, con un argumento articulador: el autor pretende narrar los proyectos e instituciones en que ha participado, innovado y cambiado su estatus, incluso hasta la ruptura, como hizo en el Instituto Mexicano del Seguro Social (IMSS),

Profesor-Investigador del Centro de Investigaciones y Estudios Superiores en Antropología Social (CIESAS), México. ORCID: http:// orcid.org/0000-00028761-5598 aziz@ciesas.edu.mx la Secretaría del Trabajo y Previsión Social (STPS), la

James W. Wilkie, y Edna Monzón Wilkie (2017). Porfirio Muñoz Ledo. Historia oral 1933-1988. México: Debate. 
Secretaría de Educación Pública (SEP) y la Organización de las Naciones Unidas (ONU).

Llaman la atención varias aportaciones del libro:

- Cómo a través de la historia de PML se cuenta una parte importante de la historia política de México.

- El narrador mismo, que sorprende por su memoria ancha y precisa para contar hechos y recordar fechas, nombres y argumentos exactos de lo que se dijo, se negoció o se rompió.

- La narrativa, que enmarca a un actor político que se desdobla en varios roles, que a su vez son los que estructuran las seis partes o capítulos del libro: el estudiante, el servidor público, el dirigente político, el diplomático, el educador y el miembro de la oposición. Cada parte tiene diferentes historias y densidades, pero en todas existe un sentido de identidad.

- El manejo del tiempo. Si tomamos como referencia el momento en el que se realizaron las entrevistas (19871988) que dan origen al libro, es importante señalar que han pasado treinta años, y en ese periodo ¡vaya que el país, sus problemas nacionales y sus desafíos se han transformado! Sin embargo, a pesar de que la narración del libro recorre cinco décadas, parece que lo único que cambia es el narrador, aunque en realidad vemos la transformación de un país, el largo tránsito de un autoritarismo a los inicios de un proyecto para dejar atrás al partido hegemónico, los muchos cambios dentro de una estabilidad que poco a poco se fue moviendo de un modelo de desarrollo a otro. En suma, se ven los fracasos de México en la búsqueda por su modernidad.

- La visión del narrador, que por lo ya señalado está ubicada en un momento del país que sintetiza un punto de su historia, el de una ruptura y la formación de una nueva utopía de futuro: la construcción de una democracia en México en los últimos años del siglo XX. 
- Los silencios y los tonos bajos que el libro narra, esto es, aquellos momentos oscuros de la historia del país. Las decisiones y momentos en los que PML estaba, pero no estaba, como el 68 y el diazordacismo. El funcionario responde que nunca ha llegado a saber quién tuvo la culpa de lo acontecido el 2 de octubre de 1968, y compara la represión en México y la sudamericana, diciendo que en el país ha sido marginal, pero permanente, como un chipi-chipi.

Esta historia oral tiene como líneas conductoras a la argumentación de la política y la transformación del narrador: de sus años de estudiante habitante de la colonia Del Valle a universitario en París; de su regreso a México y sus resistencias a entrar a trabajar en el Gobierno a su transformación en un funcionario de altos vuelos; de ser aquel joven asesor que hacía textos y discursos en el sexenio de López Mateos a convertirse en secretario de Estado; de ser el político que aspiró a la silla del águila a transformarse en el dirigente del Partido Revolucionario Institucional (PRI); de fungir como diplomático presidente del Consejo de Seguridad de la ONU -en dos ocasiones- a ser el político que tuvo la idea - ¿ingenua?- de que el PRI se podía democratizar, o de que el sistema político era democratizable desde adentro. En una parte del libro, dice PML: "En los años cincuenta pensábamos que el sistema era reformable desde dentro" ( $p$. 143). Quizá también lo pensaron en los sesentas, setentas, y ciertamente en los años ochenta.

La narrativa de PML muestra con mucho detalle que dentro del Estado mexicano había una pugna entre corrientes distintas, entre grupos de poder y entre camarillas, que llegó a un punto de definición con el triunfo de la tecnocracia y la exclusión de la otra corriente, heredera de la Revolución mexicana. Esa fractura se hizo irremediable, 
y fue una condición del proceso democratizador vivido de 1988 en adelante.

La última parte del libro es la que personalmente resulta más cercana porque la viví y la estudié. Expresa a un político que, junto con otros, genera la mayor ruptura en el partido oficial. En 1988, no sólo la llamada corriente democrática (CD) rompió con el PRI, sino que el aparato entero se partió en dos y dio un vuelco la competencia electoral, se inauguró el sistema de tres grandes fuerzas partidarias, la izquierda histórica se reencontró con el cardenismo, se generó un proyecto económico diferente a través de un severo ajuste que lastimó a las mayorías del país, se iniciaron las grandes alianzas entre el PRI y el Partido Acción Nacional (PAN), se reprimió a la izquierda perredista y se acordó con la derecha panista, y llegó al poder una tecnocracia que instaló en el poder de forma permanente hasta el triunfo, en 2018, de Morena en la Presidencia de la república y la mayoría en el Congreso.

Una característica de PML como político ha sido su visión de Estado, un sentido que poco a poco se ha extraviado en la clase política de las últimas décadas. El currículum y la historia del narrador muestran a un país en donde el prestigio y la calidad de sus funcionarios eran un factor de peso dentro y fuera de México. Decíamos que es una costumbre que se ha extraviado porque, entre tecnócratas e ignorantes, la clase política ha bajado de nivel de forma grosera.

En su relación con el poder presidencial, están muy claras las opciones y las preferencias de PML, pero también quedan cristalinas sus diferencias, sus antipatías, sus filias y fobias. Hay cercanía con López Mateos y Echeverría, incluso con José López Portillo, pero hay diferencias con Díaz Ordaz y con De la Madrid.

A veces, he pensado que PML tiene el afán por contar la historia política del país como si él fuera un eje central. En estas novecientas cuarenta páginas, da un testimonio de 
una incontable lista de propuestas, iniciativas, creaciones institucionales, textos, discursos, acuerdos, que se deben a su operación y a su talento. En efecto, son muchos años, y el narrador ha estado en mil batallas. Durante la lectura del libro, me acordé lo que dicen en las clases iniciales de Sociología: no hay que creer lo que los actores políticos o sociales dicen de sí mismos, porque eso es materia de sospecha. Muchas de las experiencias de PML quedan muy lejanas en el tiempo, y sólo se puede tener aproximación a ellas por medios indirectos. Sin embargo, cuando llegué a la última parte del libro, la de la ruptura y la CD, 1988 y sus consecuencias, personalmente pude comprobar que la visión del narrador se apega a lo que había analizado en otras fuentes.

En el país que nos narra PML, había creación de instituciones, una dinámica de exclusión -aunque combinada con mecanismos de inclusión-, y, sobre todo, un Gobierno que tenía deseo de Estado, como dice Marc Auge. Hoy, la tecnocracia se dedica a vender instituciones, a desregular los intereses empresariales y a descafeinar las reformas. Ha cambiado tanto el proyecto de país que sus vectores están fuera de las fronteras nacionales: lo que gobierna es el mercado internacional y el gran capital global.

En este libro, la visión de país está amarrada a una identidad nacionalista. Nacionalista se define el narrador, y además agrega otros dos acentos: tercermundista y latinoamericanista.

El tiempo del narrador termina con la creación del nuevo partido, el de la Revolución Democrática (PRD). Lo que sucede después es conocido. ¿Qué tanta similitud hay entre la caída del PRD, que ha terminado por aliarse como subalterno con el panismo, y la llegada del desencanto y el sistema partidocrático, que hoy dan cuenta del fracaso democrático? 
Muchas historias vinieron después del nacimiento del PRD, con la llegada del salinismo, y PML las vivió ya desde la oposición: el cambio a un modelo neoliberal y la inserción subordinada del país en el mercado mundial desde una estrategia exportadora, con maquila, mano de obra barata y el Tratado de Libre Comercio de América del Norte (TLCAN); el zapatismo; la creación del Instituto Federal Electoral (IFE) y la reforma de 1996; el inicio de los Gobiernos divididos; el triunfo perredista en la Ciudad de México; la alternancia presidencial; el intento fracasado de una reforma del Estado; el acercamiento con el primer Gobierno de alternancia; el conflicto electoral de 2006; la salida de PML del PRD; la constitución de la CDMX; y muchos otros acontecimientos que probablemente llenarían otra historia oral.

Este libro llegó en buen momento para contar las historias de un hombre público y sus batallas, pero también por el momento actual, con una sucesión en donde estuvo en disputa, como en 1988 y en 2006 , el proyecto de nación para los próximos años. Una diferencia notable con las dos fechas anteriores fue que en 2018 ganó la propuesta alternativa al modelo hegemónico, que ha entrado en una crisis incierta.

De la historia según PML, retomo una afirmación para cerrar. Está en el libro, pero hoy cobra una especial relevancia, sobre todo por el grado de corrupción al que han llegado el sistema y el Gobierno: "No haber aceptado estar nunca en la complicidad del dinero me dio un grado de independencia grande respecto a los miembros del sistema" (p. 481). 